\title{
Understanding the quality of early \\ estimates of Gross Domestic Product
} Graeme Chamberlin, Sumit Dey-Chowdhury and Robin Youll

\section{Office for National Statistics}

\section{SUMMARY}

There has been considerable attention paid in recent months to Office for National Statistics early estimates of Gross Domestic Product (GDP). These estimates provide a timely indication of the evolution of the economic cycle, and there has been particular interest in their reliability, given the potential for the estimates to be revised.

This article describes the context in which the official estimates of GDP are produced, and examines the reason for revisions to early estimates. It goes on to discuss how these revisions can best be analysed over different maturities of the estimates and points out some potential pitfalls. Based on this discussion, it offers guidance on the best approach to understanding the revisions cycle and for interpreting the published information on revisions.

The article then presents the results of analysis of a new real time database for GDP growth in the UK, which contains a time series of estimates back to 1961. Over the period since the mid-1990s, revisions have been much smaller than previously, perhaps reflecting the relative stability of the economy over this time.

The article concludes by discussing the issues surrounding the use of bias adjustments for GDP.

\section{The first estimate of GDP}

imely statistics relating to the growth of real GDP (that is GDP

after adjusting for changes in prices) are needed by users so that their decisions better reflect current economic circumstances. ONS's preliminary GDP Statistical Bulletin is designed to meet this need. The release is published just 25 days after the reference quarter, making it the fastest official estimate of its type produced by any major industrialised country. The timeliness of this release is consistent with longstanding demand from users for quickly available information to support analysis in relation to economic policy.

The preliminary estimate of GDP is based on information requested from nearly 40,000 businesses relating to their turnover in the first two months of the relevant quarter. The remaining month includes data from a further 20,000 returns. In addition, each month ONS collects prices on nearly 200,000 individual products from around 30,000 retail and other businesses. This information is used to adjust the estimates of GDP into 'real terms', that is by removing the effect of inflation.

However, at the time this first estimate of GDP is produced, these data cover only about 40 per cent of the economic activity which will be included in the more mature estimates published around 12 months later. The remainder of the early estimate is based largely on forecast models. As time progresses, the data content of the GDP estimates increases, reducing the need to forecast. As data from annual surveys and administrative data become available, ONS uses Supply and Use analysis to reconcile fully the three different measures of GDP, based on the Output, Income and Expenditure approaches. These annual estimates form a benchmark against which the quarterly estimates are aligned. This leads to further revision of the estimates. Also, new sources and methods better to measure the evolving economy are introduced periodically. These, too, can lead to revisions to the estimates. As these methodological developments are openended, in principle GDP could be revised in perpetuity. In that sense, there is no such thing as a final estimate of GDP. See Mainwaring et al 2007.

This process of updating estimates as more information becomes available, and the consequent revision of the earlier estimates, means that there is a necessary and explicit trade-off between the timeliness and reliability of the early estimates. In 2004, the then Monetary Policy Committee (MPC) member, Marian Bell commented

\footnotetext{
'The Monetary Policy Committee recognises that revisions are inevitable. Indeed so far as they bring us to a better understanding of reality, we welcome them.' She continued 'There is inevitably a trade-off between timeliness and accuracy, but in general, we would prefer early imperfect data to late perfect series - it gives us something to work with.'
}

Later that year, Rachel Lomax, the then 
Deputy Governor of the Bank of England said

'If the ONS waited two or three years before publishing their first estimates they would have reasonably complete information. But it would be of rather limited use for policy purposes.

We need more timely indicators of economic activity, even though these will tend to be less accurate than later estimates.'

Even though there is a general understanding of why revisions occur, they still present a challenge to policy-makers in forming their current assessment of the economy. A key question is how much weight should be placed on the early estimates if they continue to be revised, often for several years afterwards. This is especially pertinent when policy is set proactively, such as monetary policy. The Bank of England has referred to this as 'dealing with data uncertainty' (see Ashley et al 2005).

The next section describes how ONS reports these revisions and how this enables users to understand better the quality of the early estimates and makes explicit the tradeoff made between timeliness and reliability.

\section{How ONS reports information on revisions}

As part of the commitment to improving the quality of economic statistics, ONS monitors and publishes extensive information on revisions. This is part of its open policy towards revisions which includes incorporating, quickly and transparently, new information into the published estimates, as it arrives. Revisions information is published in Statistical Bulletins, in on-line spreadsheets and in an annual article in the Economic and Labour Market Review (see, for example, Murphy 2009). These practices are amongst the most transparent in the world.

The availability of information on revisions helps users understand the evolution of the quality of the estimates. Seen in this way, revisions should not be considered as necessarily errors, but rather as part of the process by which economic statistics are produced.

For analytical purposes it is convenient to store information on revisions to GDP in the form of 'revisions triangles', or real-time databases as they are sometimes known.

Box 1 describes how these data are arranged and their importance in the analysis for revisions. The key point here is that the triangles present revisions for different 'maturities' of GDP. The first published estimate of growth in real GDP for a period is said to be of maturity 1 (a M1 estimate). When this is updated the following month, it has maturity 2 (a M2 estimate). Revisions calculated between estimates of different maturities (say between M1 and M3) ensure that the estimates are of the same 'age', this is they have all had the same length of time to mature. For example, in the case of a comparison of M1 an M3 estimates, all estimates have had 2 months to mature. An average of revisions with the same age can then be calculated which provides an expected revision between different maturities of the estimates based on the historical data.

Through analysis of the revisions triangles, it is possible to look for patterns in revisions and, in particular, to assess whether there might be a dominant

\section{Box 1}

\section{ONS revisions triangles (or real time databases) of GDP}

ONS makes available on its website information about revisions to key economic statistics, including GDP. This includes so called 'revisions triangles' which are published in the form of spreadsheets, and allow users to develop their own analysis of the revisions history of GDP. The spreadsheets also contain some summary statistics of the revisions.

These databases present revisions to GDP in the format of a 'triangle' of published estimates, as shown schematically in Table 1.

Table 1 The ONS revisions triangle

\begin{tabular}{llllll}
\hline $\begin{array}{l}\text { Release date } \\
\text { (or 'vintage') }\end{array}$ & $\ldots$ & 2007 Q4 & 2008 Q1 & 2008 Q2 & 2008 Q3 \\
\cline { 2 - 6 } & $\ldots$ & $\ldots$ & & & \\
March 2008 & $\ldots$ & M3 & & & \\
April 2008 & $\ldots$ & M4 & M1 & & \\
May 2008 & $\ldots$ & M5 & M2 & & \\
June 2008 & $\ldots$ & M6 & M3 & & \\
July 2008 & $\ldots$ & M7 & M4 & M1 & \\
August 2008 & $\ldots$ & M8 & M5 & M2 & $\ldots$ \\
$\quad \ldots$ & $\ldots$ & $\ldots$ & $\ldots$ & $\ldots$ & $\ldots$ \\
\hline
\end{tabular}

The table shows, for example, that the first estimate of GDP growth for the first quarter of 2008 (2008Q1) was published in the April 2008 preliminary GDP Statistical Bulletin. This is referred to as the M1 (or month 1) 'maturity'. The second estimate of the same growth rate for 2008Q1 was published in May 2008 in the Output Income and Expenditure Statistical Bulletin, referred to as the M2 (or month 2) maturity.
The point about the revisions triangles is that they show how each estimate of GDP 'evolves' over time as more information becomes available. They therefore provide a history of each estimate as a series of maturities (M1, M2, M3 etc).

To understand the data presented in the triangles, it is important to distinguish between three different aspects of the data:

- the Period is the quarter to which any given estimates relates, that is there are a series of different estimates for the period 2008Q1, starting with the M1 estimate published in April 2008

- the Maturity can be thought of as the 'age' of a given estimate, for example the M1 estimates represent the estimates of age 1 month (that is the first published estimates for any period). Similarly, estimates of maturity 3 (M3 estimates) are three months old

- the Vintage is a given release of data at a given point in time. It is the temporary state of the quarterly GDP time series composed of estimates which all have different maturities

The difference between maturities for any particular estimate (say between the M1 and M3 maturities) is the revision to that estimate between those two maturities. Presented in this way, that is as a set of differences, the triangles show how estimates of GDP have been revised. This allows the calculation of an average, or expected revisions between different maturities. 
direction in the revisions process (which would indicate a bias in early estimates). ONS carries out extensive analysis of this type, as part of its quality assurance process, to help avoid unnecessary revisions in future estimates.

The next section considers how this published information can be used to develop understanding of the revisions process.

\section{Interpreting and analysing information on revisions}

Revisions to estimates of the growth of the volume of GDP arise for a variety of reasons. These include:

- as late responses received from businesses in ONS sample surveys are incorporated into the estimates;

- from regular and planned updates to the structures used to compile aggregates (such as updating of the gross value added weights based on annual surveys);

- one-off methodological improvements - for instance, the introduction of annual chain-linking, and changes in the national accounting framework.

Occasionally, there will also be revisions to GDP arising from the correction of errors and mistakes. But such cases are very rare.

ONS monitors the impact of each

type of revision as a standard part of the compilation of estimates of GDP. (See Mainwaring et al 2007 and Youll 2008.) It is important as part of this monitoring to distinguish between routine revisions, which arise from the regular updating of the estimates, and those which arise from changes to methodology.

During the routine revisions cycle, which consists broadly of the period from the preliminary (that is M1) estimate to the estimate published 24 months later (M24), revisions usually arise from incorporating late data, updating the seasonal adjustment, and from benchmarking of the quarterly estimates of GDP to more complete annual data sources. Beyond 24 months, revisions are more generally caused by changes to methodology, including changes to the international national accounting standards under which GDP is compiled.

The important point here is that these later methodological changes effectively 'move the goalposts' in that they represent fundamental changes in the basis of measurement. Accordingly, any comparison of the first estimates with those made 4 or 5 years later has to be made with great care. Any such comparison will include the effects of the specific methodological improvements made over that particular period. No doubt, future methodological improvements will also be made, but their effects will depend on their specific nature. The underlying point is that information about past revisions incorporating the effects of methodological change can not be used reliably to anticipate the likelihood or extent to which the current estimates of GDP will be revised over a similar sort of timescale.

In an ideal world, it would be helpful to know, with a high degree of certainty, what such future changes in methodology might be, and to predict in advance their likely effect in generating revisions to the current estimates of GDP. In reality, this is plainly not possible. Many of the methodological improvements to constructing GDP introduced in the UK in the last 10 years, for example, represent the outcome of years of methodological research and development around the world.

The measurement of the economy faces similar challenges to other scientific disciplines, where the current state of development is used as the basis of measurement in the full knowledge that this will improve as research continues. GDP measurement faces the additional challenge that the economy itself evolves, and so the tools needed for its measurement also need to keep up with those changes.

As a practical example, the latest estimate of real GDP growth for 2003Q1 incorporates the effects of a number of significant methodological changes which were not incorporated in the preliminary estimate when it was published in April 2003. These include chainlinking of the estimates, the addition of estimates of 'own account' software, an improved approach to the measurement of Financial Intermediation Services Indirectly Measured (FISIM), and a series of improvements to the measurement of government output, following the recommendations of the Atkinson Review.

All of these developments have given rise to revisions. In principle, ONS could avoid any revisions arising from methodological improvements by placing a permanent embargo on such changes. But that would scarcely be a sensible policy.

It is important to be aware of the potential for future revisions arising from methodological improvements. However, for the reasons discussed, comparative analysis that fails to allow for their effects can lead to fallacious and misleading conclusions. For practical purposes, consideration of revisions due to nonmethodological causes is likely to give a sounder basis for assessing the quality of early estimates.

Normally, the bulk of revisions from non-methodological causes (that is incorporation of late and benchmark data) are taken on within 24 months of the first estimate being published. It is over this timeframe, therefore, that analysis of revisions is likely to be of most value in assessing the quality of the early estimates.

The next section, and much of the remainder of this article, examines the quality of early estimates of GDP based on analysis of a new long-run database of revisions.

\section{A new long period database of GDP revisions}

As noted earlier, revisions triangles are collections of different maturities of GDP estimates which show the actual estimates of real GDP growth available to users at specific points in time.

Hitherto, ONS has published website revisions triangles for GDP going back to 1993 (see www.statistics.gov.uk/statbase/ Product.asp? vlnk=13560). However, this is a fairly limited sample and for most of this period, the UK economy was unusually stable, by historical standards. To overcome these limitations, ONS has built a revisions triangle for real GDP growth estimates for a much longer period, back to 1961 . This information will now be published on the website.

The first GDP estimate in these triangles pertains to 1961Q2 and the last to 2009Q2. Data have been collected for the expenditure measure of GDP, so the triangles should be similar to the real time database constructed by Castle and Ellis (2002). The new triangles differ from the revisions triangles ONS has published previously, in that the different GDP maturities relate to successive monthly journal publications and not to estimates published in Statistical Bulletins (that is Preliminary Estimate; Output, Income and Expenditure, Quarterly National Accounts and Blue Book). But because the underlying data are the same, any differences will be small.

\section{Features of the long-run real-time GDP dataset}

Figure 1 presents eight different maturities of GDP growth between 1961Q2 and 2009Q2. These are the first published estimate (T) for each quarter, and then the respective 


\section{Figure 1}

\section{Real time GDP data}

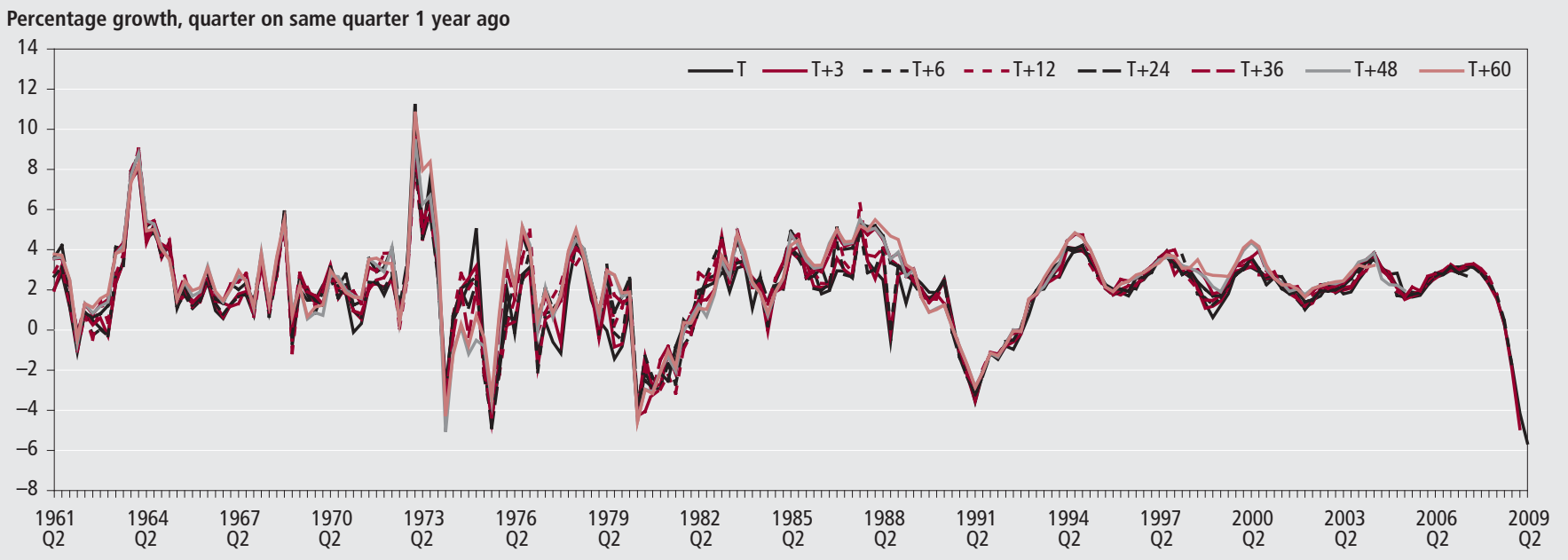

Source: Economic Trends and Economic \& Labour Market Review

\section{Figure 2}

\section{Real time GDP data, $\mathrm{T}$ and $\mathrm{T}+60$}

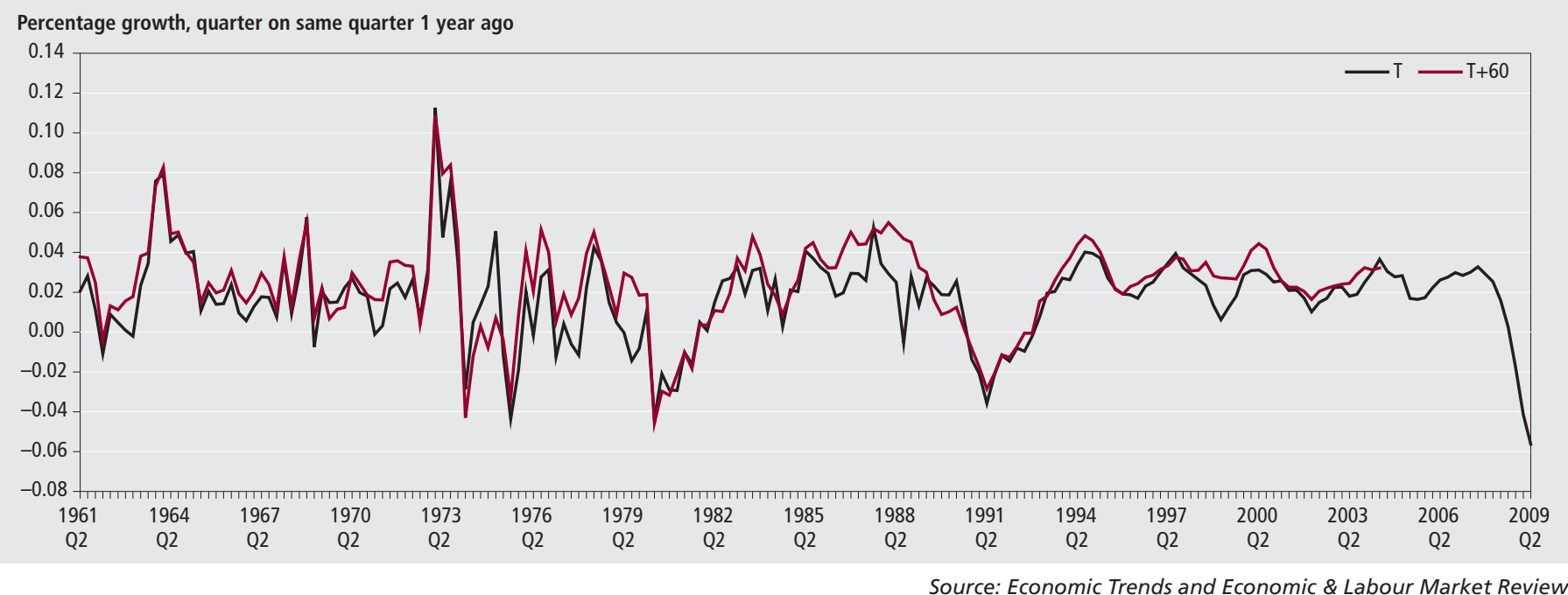

data three months $(\mathrm{T}+3)$, six months $(\mathrm{T}+6)$, 12 months/one year $(\mathrm{T}+12), 24$ months/ two years $(\mathrm{T}+24), 36$ months/three years $(\mathrm{T}+36), 48$ months/four years $(\mathrm{T}+48)$ and 60 months/five years $(\mathrm{T}+60)$ later. This is a sample of the data held in the database, although any data maturity published since 1961 could have been presented.

Plotting a collection of different data maturities in the same chart gives a visual impression of the reliability of the successive maturity estimates. Ideally, each maturity would give the same estimate for a particular period, so they would all coalesce into the same line. At the other end of the spectrum, successive maturities wildly diverging would indicate poor reliability.

While the chart does not show estimates coalescing into a single line, the overwhelming impression is that the successive maturities have been closely concentrated for most quarters.
Successive estimates of growth rates have not generally changed by large amounts sufficient to warrant substantially different interpretations of the economy's position or performance.

There are partial exceptions to this conclusion for a few quarters. In particular:

- In the second half of the 1980s, there was a period of consistent upward revisions, particularly in 1987 and 1988. Here the data was pointing to a slowdown in growth, and while this was eventually the case the actual slowdown, as described by the mature data, was far more gradual. The subsequent Pickford Review (1989) recommended a number of changes, the most significant of which was the publication of a single measure of GDP instead of separate output, income and expenditure measures as before.
- More recently, there was a period of significant upward revisions during 1998-99. Earlier estimates of GDP had pointed to a slowdown in growth, a view backed by business survey data such as the widely monitored Purchasing Managers Index (PMI). The Asian financial crisis of 1997-8 and the Russian crisis of 1998 which was then matched in Latin America, led to uncertainty and instability in the global economy at this time, but there was also an easing in UK monetary policy that supported domestic demand. This was picked up in later data maturities which showed the economy, especially aggregate demand, to have been more resilient in 1998 and stronger in 1999.

As a special case of Figure 1, Figure 2 directly compares just the first data maturity with that published five years (60 months) 
later. This is a harsh test since it includes revisions arising from methodological improvements as well as those from other sources. For the reasons given above, care is therefore needed in the interpretation.

Nevertheless, these data suggest that, over a long period of time, first estimates have provided a good guide to the state of the economy - as described by estimates at maturities 5 years hence. So, although early estimates are likely to be revised, and this creates uncertainty for users, it seems rare that the data are changed to such an extent as to affect fundamentally the economic story they portray.

\section{Metrics to help assess the quality of GDP}

The quality of the National Accounts has a number of dimensions. For this reason, most National Statistics Institutions including the ONS - refrain from trying to construct a single measure of the quality of GDP data. Instead, quality is expressed with respect to the standard European dimensions of quality - accuracy, timeliness, punctuality, accessibility, clarity, comparability and coherence. Box 2 explains how ONS defines each of these in assessing the quality of GDP data.

For the preliminary estimates of GDP, the key quality issues would seem to be how early, and how accurately, its value can be assessed with some certainty. This relates to the accuracy benchmark, but also to relevance and timeliness in their availability and demand for use in policy-making. This approach to measuring quality puts information on revisions at the centre of the quality assessment.

Notwithstanding the caveats at the start of this section, appropriate metrics can be helpful in assessing the quality of GDP. Many different approaches can be used to summarise revisions, some of which are considered below.

\section{Mean revisions}

Mean (arithmetic) average revision between the estimate of GDP for time $\mathrm{T}$ at time $\mathrm{T}+i$ and time $T+j$ is defined as:

$$
M R_{i, j}=\frac{\sum_{t=1}^{N}\left(y_{t, i}-y_{t, j}\right)}{N}
$$

Where $N$ is the number of quarters in the span of estimates considered and $y_{n, T+i}$ is the $i$-th maturity of GDP data pertaining to the $n$-th quarter

Figure 3 presents the mean revisions between the first published estimate and those published 24 months later over four sub-samples from the long-run dataset. These are calculated as the quarter on quarter growth rate for GDP.

The key observations seem to be:

- mean revisions for all these sub-periods are all positive

- however, mean revisions have fluctuated considerably over time. In the most recent period (1995Q1 to 2004 Q2), they were lower than in earlier periods, and, at only 0.05 per cent, insignificantly different from zero.

Although interesting as a broad summary description, mean revisions are of limited value for judging the size and significance of revisions. This is because average revisions can be relatively low simply because, in a given period, large downward revisions have been offset by large upward revisions.
For this reason, mean squared revisions (MSR), or sometimes mean absolute revisions (MAR), are usually preferred.

Mean squared revisions (MSR) and Mean Absolute revisions (MAR)

The mean squared revision between the estimate of GDP for time $\mathrm{T}$ at time $\mathrm{T}+i$ and time $\mathrm{T}+j$ is defined as:.

$\operatorname{MSR}_{i, j}=\frac{\sum_{t=1}^{N}\left(y_{t, i}-y_{t, j}\right)^{2}}{N}$

By squaring revisions, the estimate penalises large revisions at the expense of smaller ones.

In absolute terms, the mean absolute revision is defined as:

$M A R_{i, j}=\frac{\sum_{t=1}^{N}\left|y_{t, i}-y_{t, j}\right|}{N}$

In this case, large revisions would be treated as proportionately no more serious than smaller ones. But a downward revision would not offset an upward one for a different period - both being treated as representing a negative characteristic.

From a user perspective, a few large revisions to GDP are more likely to disrupt the reading of the economy than a preponderance of small ones, so producers of economic statistics are more sensitive to avoiding large revisions. For this reason, MSR is often preferred to the MAR, as a measure of the impact of revisions. Sometimes this is presented in its square root form, which essentially puts the metric onto the same scale as the revisions themselves.

\section{Box 2}

\section{Dimensions for assessing the quality of GDP}

The standard European dimensions of quality of statistical estimates are presented below.

\section{Relevance}

The degree to which statistical product meets user needs for both coverage and content

\section{Accuracy}

The closeness between an estimated result and its (unknown) true value.

\section{Timeliness and punctuality}

Timeliness refers to the lapse of time between publication and the period to which the data refer. Punctuality refers to the time lag between actual and planned dates of publication.

\section{Accessibility and clarity}

Accessibility is the ease to which users can access the data, also reflecting the formats in which the data is available and the availability of supporting information. Clarity refers to the quality and sufficiency of the metadata, illustrations and accompanying advice.

\section{Comparability}

This is the degree to which data can be compared over time and domain.

\section{Coherence}

The degree to which data that are derived from different sources or methods, but which refer to the same phenomenon, are similar. 


\section{Figure 3}

\section{Mean revisions between $\mathrm{T}$ and $\mathrm{T}+24$}

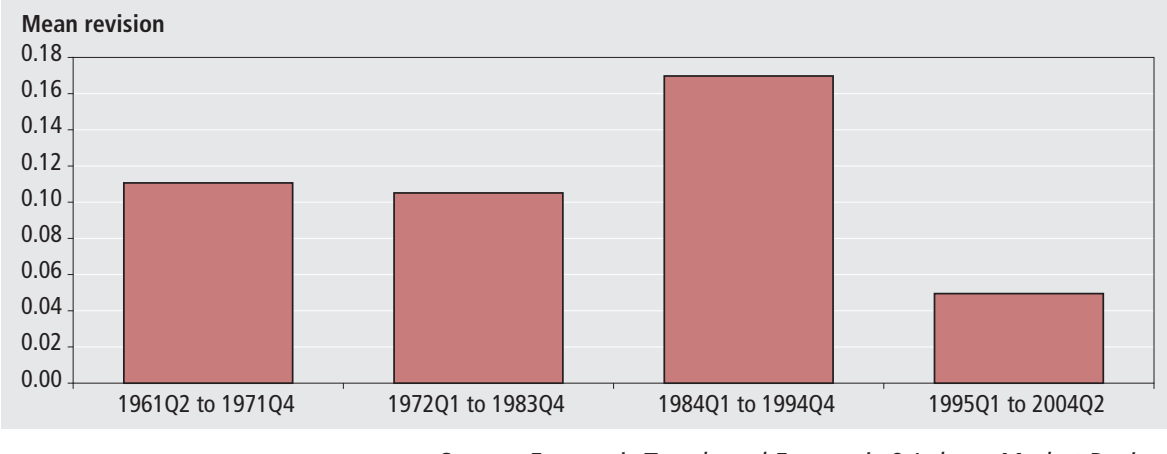

Source: Economic Trends and Economic \& Labour Market Review

\section{Figure 4 \\ Mean squared revisions over different periods}

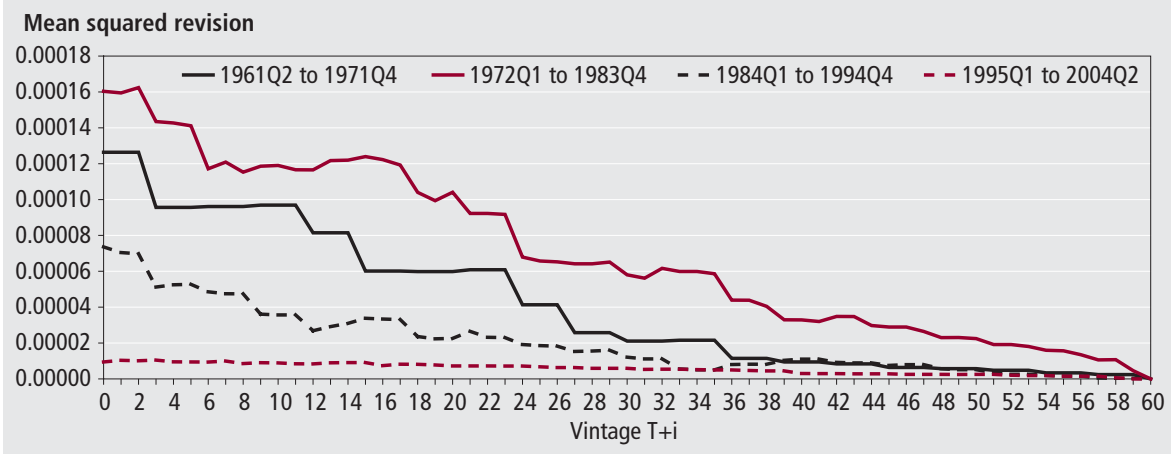

Source: Economic Trends and Economic \& Labour Market Review

\section{Figure 5 \\ Comparison of the T to T+60 MSR with the Variance of the T+60 Maturity}

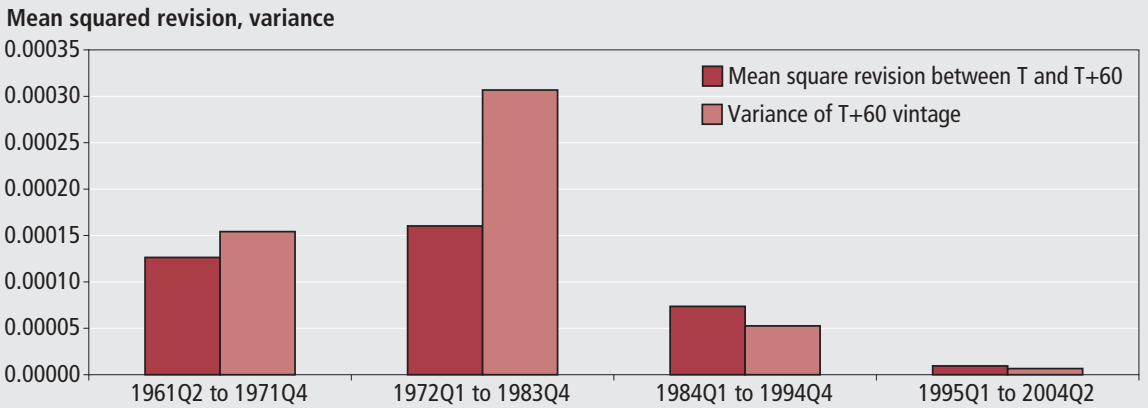

Source: Economic Trends and Economic \& Labour Market Review

Using the same periods as in Figure 3, the mean squared revisions with respect to the T+60 maturity are shown in Figure 4.

While, for completeness, MSRs are shown up to maturities up to $\mathrm{T}+60$, as noted earlier, this represents a harsh test since it includes in the measure effects of revisions due to methodological improvements.

Nevertheless, the chart demonstrates a clear improvement in the quality of early GDP estimates in the most recent span compared to other periods. This reflects not just lower revisions between 1995Q1 and 2004Q2 (see Figure 3), but also a much smaller incidence of large revisions.
It should be borne in mind, however, that this improvement in quality may, at least in part, reflect the fact that the economy has been relatively stable over this last period. (Data relating to revisions stemming from the recession of recent quarters are obviously not yet available to include in the analysis.) Earlier estimates of GDP might be expected to be better relative to later maturities when the economy is growing smoothly than at times when there were sharper swings in the pace of economic growth. Figure 5, though not conclusive, gives some support to this hypothesis.

For the most recent period, 1995 to
2004 , there has been a sharp decline in the mean squared revisions of the first published versus the $T+60$ published data, as compared with previous periods. However, the variance of the final data has also fallen considerably - as a result of the relative stability of the UK economy over this period. Simply put, it may be easier for earlier estimates accurately to predict later data maturities if the economy is less prone to significant fluctuations in activity or shocks.

\section{Should early estimates of GDP be adjusted for bias?}

Bias is defined as the mean revision (MR) over a given period of time. It is important to monitor carefully and continuously for its presence because, if persistent, it would indicate early estimates as being unnecessarily suboptimal. In particular, if it was the case that the direction and size of future revisions could be confidently predicted, as of now, then it would be possible to adjust for this bias straightaway. It would therefore be possible to arrive at the likely later maturity of estimate, deemed to be more reliable, at an earlier point.

Bias adjustments, if available, might therefore be a tool that could be used to improve the early estimates. The Bank of England has undertaken considerable and impressive research into this (see Cunningham et al 2007). However, the feasibility of such adjustments depends upon the bias on which they are based being non-zero, and persistent and stable.

Some initial evidence as to whether these conditions hold is provided by Figure 6 . This presents a five-year rolling average of revisions between the first published data maturities and a number of subsequent ones. The averages have been centred so that it is easier to monitor the timing of different bias.

The main observations are:

- in general, over the period 1963 to 2006 as a whole, bias has generally been positive implying that early data maturities are more likely to be revised upwards. However, there have been periods where the GDP data has been revised downwards

- over a long history of data, the size of bias in GDP is unstable. It looks as if it may also follow a pro-cyclical pattern, though the correlation is far from perfect

- since the early 1990s, the upward bias to GDP estimates has been small. The routine element of the bias (that is that 


\section{Figure 6}

\section{Rolling five year (centred) average of GDP revisions}

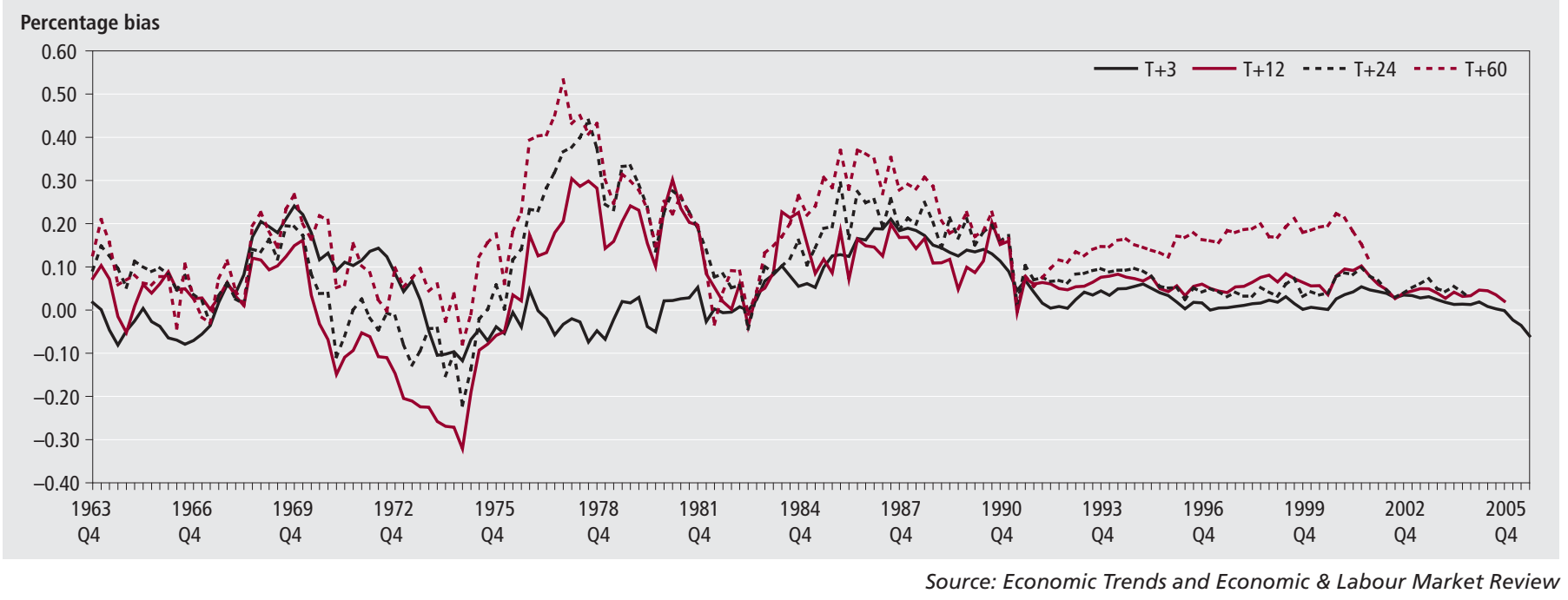

\section{Box 3}

\section{Case study in bias adjustment}

Cunningham et al 2007 describe a state-space model to extract signal from noise in order to correct early ONS estimates for bias.

The paper aimed to produce a model to predict future movements in GDP estimates based on earlier ones and thus effectively reduce the future revision to these modelled estimates.

The Bank's paper and the wider issue of bias adjustment were discussed at the Government Statistical Service Methodology Advisory Committee in May 2008. Following this, ONS developed a research project, in conjunction with Professor Fred Smith of Southampton University, to look again at this issue.

The research analysed the mean revision between different maturities of estimates relating to the periods 1993Q1-2005Q2 (consistent with the Bank's dataset). These were tested to establish if the changes were significantly different from zero. A 'split sample' approach was also used (taking 1993Q1 - 1999Q1 and 1999Qq2-2005Q2) to test the stability of the results. Broadly, the results were:

- historically there is some evidence of bias in early estimates of GDP, certainly in the 1980s and early 1990s

- however, it is not clear that this has persisted into more recent periods. Testing revealed that revisions up to the time of the annual national accounts Blue Book produced two years after the relevant initial estimates were small and not significantly different from zero for recent data (1999Q22005Q2)

In general terms, the research concluded that revisions are not sufficiently large, regular or predictable to be able to support any process of bias adjustment. which emerges from routine regular revisions, occurring up to $\mathrm{T}+24$, as opposed to that which comes from unpredictable methodological changes) averages around only 0.05 percentage points.

These circumstances do not augur well for the success of incorporating bias adjustments into early estimates of GDP. Box 3 summarises more formal analysis that has been undertaken. Its conclusions confirmed that incorporating bias adjustments intended to improve early GDP estimates was not currently viable. However, ONS will continue to monitor the evidence from revisions carefully, in respect of its implications for this conclusion. In addition, if causes of possible prospective bias should be identified - from the way data is collected, for example, or from methodologies that are used - ONS would expect to deal with those sources of bias as quickly as possible.

\section{Conclusions}

This article has examined the nature of the revisions process as it affects the estimates of GDP, and discussed ways to interpret the published information on revisions.

It has also presented some new analysis of revisions, based on a new long-run dataset for estimates of GDP, covering 1961Q2 to date.

Finally it has looked at the case for making an explicit adjustment to early estimates of GDP to factor in potential future revisions.

Broadly, the analysis in the article concludes:

- revisions are driven by two basically distinct processes: routine revisions arising from the addition of new information, and one-off revisions reflecting largely methodological improvements resulting in part from changes to international standards of measurement

- conflating these two sources of revision can lead to erroneous conclusions about both the quality of the early estimates of GDP and the extent and direction of potential future revisions

- comparison of the preliminary estimates with those published around two years later provides a reasonable basis for making like-forlike comparisons, and is helpful in understanding the underlying revisions process

- while, in an ideal world, it would be helpful to be able to predict in advance 
the effects of future methodological improvements, in the real world, that is clearly not possible.

Using the new long run data base of revisions, which has now been made available, to analyse revisions to GDP over the last 50 years suggests that:

- revisions have more often than not been upward, but not always

- the pattern of revisions has changed over time. Broadly, there looks to be some correlation with the cycle but the relationship is far from exact

- since the mid-1990s, revisions have been smaller than in previous periods. Over maturities up to $\mathrm{T}+24$, when most of the non-methodological changes will have been taken on board, the average revision is only +0.05 percentage points

- there is some suggestion that this better revisions performance may partly reflect that it is easier to measure the economy well, at an earlier time, when the economy is behaving relatively stably. The variance of GDP over this period was also lower than in previous times.
Although there is some evidence of historical upward bias in revisions, its extent and direction have not been stable or predictable. In addition, any such bias appears to have been smaller since the mid1990s, and insignificantly different from zero. Overall, revisions are not sufficiently large, regular or predictable to be able to support any procedure of incorporating bias adjustments into early estimates. ONS will, however, continue to monitor revision patterns closely, to check whether any change to this conclusion might be warranted in future. Such information on revisions will be made public quickly, continuing the current practice.

\section{CONTACT}

园elmr@ons.gov.uk

\section{REFERENCES}

Ashley J, Driver R, Hayes S and Jeffery C (2005) 'Dealing with data uncertainty', Bank of England Quarterly Bulletin Spring 2005

Bell M (2004) 'Monetary policy, data uncertainty and the supply-side: living with the statistical fog', speech to the Society of Business Economists, Wednesday 15 September 2004

Castle J and Ellis C (2002) 'Building a realtime database for $\operatorname{GDP}(\mathrm{E})$ ', Bank of England Quarterly Bulletin Spring 2002

Cunningham A and Jeffery C (2007) 'Extracting a better signal from uncertain data', Bank of England Quarterly Bulletin Autumn 2007

Lomax R (2004) 'Stability and statistics', speech to the North Wales Business Club, Tuesday 23 November 2004

Mainwaring $\mathrm{H}$ and Skipper $\mathrm{H}$ (2007) 'GDP(O) revisions analysis system: overview and indicative results', Economic \& Labour Market Review 1(10), pp 36-42 and at www.statistics.gov.uk/cci/article. asp? $i d=1879$

Murphy J (2009) 'Revisions to quarterly GDP growth and its components', Economic and Labour Market Review April 2009

Youll (2008) Dealing with potential bias in early estimates of GDP, Economic and Labour Market Review July 2008 